APA: Ávila Hernández, F. M., Villalobos Antúnez, J. V., Machado, G. y Romero Neces, L. (2020). El sistema de nominación del poder judicial y su influencia en el sistema político. El caso Venezuela: falencias y desafíos. En O. A. Agudelo Giraldo (Ed.), Derechos humanos, democracia y poder judicial (págs. 121-158). Editorial Universidad Católica de Colombia. https://doi.org/10.14718/9789585133020.2020.6

Chicago: Ávila Hernández, Flor María, Villalobos Antúnez, José Vicente, Machado, Gustavo y Romero Neces, Luis. "El sistema de nominación del poder judicial y su influencia en el sistema político. El caso Venezuela: falencias y desafíos." En Derechos humanos, democracia y poder judicial editado por Oscar Alexis Agudelo Giraldo, 121-158. Bogotá: Editorial Universidad Católica de Colombia.

doi: $10.14718 / 9789585133020.2020 .6$

\title{
EL SISTEMA DE NOMINACIÓN DEL PODER JUDICIAL Y SU INFLUENCIA EN EL SISTEMA POLÍTICO. EL CASO VENEZUELA: FALENCIAS Y DESAFÍOS
}

\author{
Flor María Ávila Hernández \\ José Vicente Villalobos Antúnez* \\ Gustavo Machado \\ Luis Romero Neces
}

\section{Introducción}

La selección de jueces y magistrados para ocupar cargos en el poder judicial en general, y en las Cortes Supremas en particular, en el contexto de los Estados Democráticos de Derecho, representa un tema fundamental para la Filosofía del

\footnotetext{
* Postdoctora en Derechos Humanos y Doctora en Filosofía de los Derechos Humanos de la Universidad de Nápoles. Magister en Ciencias Políticas y Derecho Público de la Universidad del Zulia. Docente e investigadora de la Universidad Católica de Colombia. Email: fmavila@ucatolica.edu.co.

** Postdoctor y Doctor en Derecho de la Universidad del Zulia. Editor de la Revista Opción de Ciencias Humanas y Sociales. Email: jvillalobos@gmail.com.

*** Magister en Teoría y Política Económica de la Universidad Central de Venezuela. Director de investigación e innovación del Instituto de Gerencia y Estrategia del Zulia. Email: gustavo.machado1974@gmail.com.

**** Licenciado en Lenguas Modernas. Abogado de la Universidad del Zulia. Doctor en Ciencias Humanas. Email: luisromero7@gmail.com.
} 
Derecho, la Ciencia Política, la Sociología Jurídica y la Ciencia del Derecho. Estos campos del conocimiento afrontan este tema modernamente con grandes desafíos y con no menos e inusitados dilemas.

El poder judicial representa el escenario donde el derecho se realiza, pues interactúa con los ciudadanos de forma más directa y legítima, en regímenes democráticos. Este se configura como bisagra para aliviar tensiones sociales y políticas entre la sociedad civil y el Estado, aun cuando este último pueda tener un rol de mediador de tensiones, el cual se ve truncado por su histórico carácter intervencionista, haciéndolo también un generador de conflictos.

La literatura especializada expone que esta cuestión tiende a desaparecer parcialmente desde el neoliberalismo político, exceptuando aquellos modelos de organización del Estado donde impera una fuerte posición del paradigma paternalista (Villalobos Antúnez, 2001) ${ }^{47}$. Sin embargo, y a pesar de las tensiones generadas en su desempeño, hoy estos sistemas políticos también son llamados "constitucionales", en atención a los reclamos sociales relativos al cumplimiento de sus fines, en virtud de la primacía de los principios que los constituyen, especialmente en el ámbito de la aplicación del derecho legal y legítimamente "puesto" 48 .

A estos aspectos, centrales en la configuración del Estado de Derecho y de la Teoría Contemporánea del Derecho, se les conoce como, por un lado, el "principio de autonomía" o "de autonomía de funcionamiento" y, por el otro, como "principio de independencia de poderes" o "principio de independencia". Junto con el "principio democrático", ellos conforman el hoy llamado "Estado Democrático de Derecho" (Habermas, 1998). En este se encarna, como proyecto político, la realización de los derechos que socialmente le son atribuidos al ciudadano ${ }^{49}$. Lo

47 Para una revisión del Derecho, desde los paradigmas jurídicos del Estado, en el contexto del Derecho Moderno.

48 En este texto se denomina "derecho legal y legítimamente puesto", aquel que para obtener su vigencia como norma ha seguido los procedimientos pautados por un orden jurídico determinado. Modernamente, este "derecho" es legislado a partir de esas mismas pautas, pero estatuidas por las Constituciones Políticas, justamente en el contexto del Estado Democrático de Derecho. Para más información, ver: José Manuel Delgado Ocando (1996). Sobre la evolución de este concepto en la modernidad, ver: Juan Ramón Capella (1997).

49 Esta cuestión principal, del Estado Democrático de Derecho, es analizada en el marco de los derechos sociales fundamentales, precisamente a partir de la justicia como valor indispensable para la convivencia, es decir, como elemento de estabilización de expectativas. De esta forma, la justicia solo puede ser alcanzada mediante la toma de decisiones abarcadoras de los intereses de los afectados en dichas sociedades. De allí la necesidad de que el Estado Constitucional se apropie de un procedimiento cónsono con los principios que lo fundan, para designar funcionarios judiciales en tiempos de democracia, en todas sus jerarquías y ocupaciones. Esta cuestión se analiza 
anterior hace que una gran carga, en el proceso de estabilización de expectativas, dependa del poder judicial, especialmente en situaciones de conflicto.

Dichos principios son, desde la teoría política que los sostiene, los rectores de los procesos de realización del Estado de Derecho. Por ello, en el ámbito de la independencia judicial en países democráticos, son vistos como plataforma de reconstrucción de ciudadanía y, lo más importante para el presente tema, como conformadores de la esencia de la separación de poderes, la cual hace parte en Latinoamérica de uno de los modelos de designación de jueces.

Como se evidencia en los trabajos de autores contemporáneos como Jürgen Habermas, Ronald Dworking, Luigi Ferrajoli, Norberto Bobbio o Giovanni Sartori, esta cuestión, en la historia democrática, se ha convertido en el soporte fundamental y en el principio angular de la vida en sociedad (Habermas, 1998) ${ }^{50}$.

Así, incorporar mecanismos y procedimientos idóneos para la escogencia democrática de jueces es una experiencia propia de los Estados Constitucionales modernos, que han dejado en el pasado el absolutismo político. Este implicaba que el monarca o el príncipe representara las funciones mediadoras de conflictos, designando de forma unilateral, y carente de criterios "democráticos", a los jueces y magistrados, de acuerdo a su real saber y entender ${ }^{51}$. Vale aclarar que en los regímenes dictatoriales la dinámica es otra, especialmente en aquellos donde rige o rigió la tiranía como sistema de gobierno (Capella, 1997).

No obstante, la realidad que vive la sociedad política es que en algunos sistemas de derecho, aún de tradición democrática y con sostenido arraigo histórico de sus instituciones, ha sido complejo -aunque también a veces imposible- separar de facto los poderes del Estado. Lo anterior, puesto que durante el discurrir de la vida política, el nombramiento de jueces se ha permeado de influencias de

en el presente trabajo. Respecto a la aplicación del derecho en el contexto de los derechos sociales fundamentales, ver: J. V. Villalobos Antúnez y F. Ganga (2016) Derechos sociales fundamentales: Consideraciones iusfilosóficas de sus dilemas. Aproximación utópica desde la Bioética Global. En Utopía y Praxis Latinoamericana, Año 21, No. 75, pp. 93-111. Artículo en línea, disponible en: http://www.redalyc.org/articulo.oa?id=27950107010.

50 En este sentido, Habermas considera que hay un nexo interno entre el Estado de Derecho y la democracia, especialmente como pilar estructural del paradigma constitucional del Derecho, el cual se diferencia claramente de los demás tipos de relaciones en los cuales se conforma el Derecho en occidente, a saber, el iusnaturalismo, el positivismo, el criticismo y el constitucionalismo. Ver: Habermas (1997 y 1998).

51 Sin embargo, es importante señalar que en regímenes parlamentarios como el británico, el rey o la reina aún conservan la potestad de nombramiento, al menos en el nivel de cabeza visible del gobierno judicial. Para más información ver: Ricardo Ron Latas y Pedro José Lousada Arochena (2017), Los Consejos de la Magistratura y otros modelos de gobierno judicial. 
distintos órdenes, especialmente en aquellos sistemas que han optado por delegar estas funciones al Poder Ejecutivo, incluso al Poder Legislativo, o a los Órganos Colegiados, cuya directiva es a su vez designada, ya sea directamente o por influencia del mismo Ejecutivo, como en Venezuela y Colombia.

El ejecutivo y el legislativo son dos poderes tradicional e históricamente marcados por lógicas y tendencias políticas, pues, además, en sistemas democráticos son de raigambre popular: su nombramiento legítimo generalmente se realiza a través de elecciones libres, directas y secretas y mediante votaciones públicas.

En ese sentido, la designación de jueces y magistrados está, muchas veces, mediada por diferentes conflictos políticos. Por ejemplo, en Venezuela, un país con una tradición democrática de las más arraigadas en el continente americano, hasta la década de los años noventa - una época de esplendor democrático, aunque también de crisis política- se pensaba desfavorablemente sobre este tema, el cual es de vital importancia para la democracia como sistema político.

También, siguiendo con el caso venezolano, y en lo que concierne a la legitimidad en el desempeño, es uno de los problemas que se ha intentado resolver mediante formas idóneas. Estas, al ser demandadas por la sociedad en su conjunto para administrar justicia, buscan que la democracia se levante satisfactoriamente, sorteando dichos entramados políticos. De igual manera, tienen por objetivo que la clase política sepa realizar dicha figura, en tanto valor social. Ello ocurre en lo interno de la sociedad como un todo, pero también en cada ciudadano particularmente considerado ${ }^{52}$. Lo anterior, al menos de forma ideal, puesto que, en la práctica, esto ha discurrido en sentido contrario.

A propósito del modelo de gobierno judicial, instaurado recientemente por la Constitución de 1999, en uno de los momentos de inflexión política que atravesaba la democracia de Venezuela, y en lo referido a los mecanismos de designación de jueces y magistrados, el jurista venezolano Arístides Rengel-Romberg (2003) señaló:

La consideración de estos problemas ha planteado las dudas acerca de si encomendado el gobierno de la magistratura a un órgano constituido enteramente por los mismos jueces, pueda formarse una clase judicial cerrada, con una orientación divorciada de

52 La historia democrática contemporánea de este país transita por senderos inhóspitos, en un sentido del Derecho insatisfecho. Para ver una articulación en términos de democracia e historia contemporánea, consultar Historia de la democracia, de Lucía Raynero. 
los fines del Estado a través de los demás poderes; o bien, que dejando encargada la organización y gobierno de la magistratura al poder ejecutivo únicamente, pueda sufrir, como de hecho ha sufrido, graves injerencias de la política y la arbitrariedad en la justicia (p. 15).

En este orden de ideas, el presente texto tiene como propósito el análisis del tema de la designación de los miembros del Poder Judicial, tomando como situación particular el caso venezolano. Esto, con el fin de aclarar algunas dudas, que han surcado las cavilaciones en torno al problema de la administración de justicia en tiempos de democracia y en el contexto del Estado de Derecho Constitucional, tal como lo pretende el proyecto de país, contenido en la declaratoria política de la República, plasmado en su Carta Magna de 1999.

Así, este artículo se ha dividido en las siguientes secciones, para mejorar su exposición. Se inicia con las consideraciones sobre "independencia" y "autonomía", que se han discutido en la doctrina, mediante el estudio de los diferentes modelos para la designación del gobierno judicial, dados en occidente, los cuales tradicionalmente han buscado garantizar dichos valores. Luego, se abordan algunos referentes necesarios para comprender el caso en examen, a saber, la situación de designación de jueces y magistrados en Venezuela. A continuación se hace un análisis, en las dos secciones siguientes, de las leyes que han regido el tema de la designación y del gobierno judicial. Finalmente, se dan algunas reflexiones a modo de conclusión, las cuales no pretenden agotar el tema, pues quedan todavía muchas dudas que despejar.

\section{El gobierno judicial. Consideraciones sobre independencia y autonomía}

Antes de entrar en el caso venezolano, es necesario hacer un breve análisis sobre algunas de las teorías y modelos que más resaltan en occidente, en torno al tema de la designación de jueces y magistrados. Es importante tener en cuenta que la eficacia en la operatividad de los derechos, especialmente de aquellos denominados "fundamentales", pasa por tener en cuenta que un gobierno judicial independiente y autónomo es la base principal de la imparcialidad y la objetividad en el poder decisorio que ostentan jueces y supremos magistrados. Así, puede afirmarse que en la historia de la democracia contemporánea, y del Derecho que la sostiene internamente, se han dado dos sistemas o modelos, en el contexto de 
las teorías políticas emergentes, especialmente después de la Segunda Guerra Mundial.

Esta cuestión deja ver que en el mundo occidental la tarea principal de la democracia es la de administrar justicia, la cual está, además, orientada a satisfacer siempre los intereses del Estado de Derecho en el que existen particulares e instituciones. Bajo dichas premisas, cabe observar que hay básicamente dos maneras de encarar el asunto: en primer lugar, a través del Poder Ejecutivo; y, en segundo lugar, a través de la intervención conjunta del mencionado poder y del Legislativo. Estos últimos están vinculados a la voluntad popular, al menos en las democracias erigidas por un régimen igualmente democrático. De esta manera, y a partir de esta doctrina, se acentúa la separación de poderes y se permea de legitimidad la función judicial.

Vale destacar que estos dos modelos han operado, igualmente, como formas eficaces, si se miran las consecuencias que producen en lo político las decisiones emanadas de un poder judicial legítimo. Esto hace referencia a la idea de que son las Constituciones, finalmente, las que determinan esa legitimidad, al darle vida política al sistema de nombramiento de jueces y magistrados.

Al respecto, López Guerra (2002) afirma que,

por un lado, hay el que podríamos llamar Modelo Europeo, basado en el papel cen-

tral del poder ejecutivo; y por otro lado, el que podría asimismo denominar modelo americano, que pone el acento en la división de poderes y, sobre todo, en el papel predominante de las cortes supremas (p. 250).

Básicamente, el primer modelo está relacionado con la idea de un gobierno judicial, centrado en la conformación de un órgano que dimana de las facultades constitucionales dadas al Poder Ejecutivo. Este, a través de un ministro, y luego de un Consejo de la Magistratura, da legitimidad al proceso de designación de jueces, correspondiendo a las más altas esferas políticas institucionales (Ejecutivo y Legislativo), para así designar a los magistrados y a otros funcionarios (fiscal, defensor u ombudsman, entre otros) del más alto Tribunal del País. Lo anterior se evidencia, por ejemplo, en las Constituciones de Francia (1946) e Italia (1958).

Una de las características que más resalta de este modelo, es que se centra en el traslado de las funciones de nombramiento de jueces, desde el Ministro de Justicia, hacia las de un cuerpo colegiado denominado Consejo de la Magistratura. De lo que se trata, es de que el Poder Ejecutivo intente preservar la legitimidad 
del Poder Judicial, para evitar así su propia injerencia en el mismo, puesto que el nombramiento y disposición de funciones administrativas de los jueces ha hecho que esta sea inevitable. Así lo demuestra la historia de esta institución, a pesar de los intentos de resguardar su independencia y autonomía.

Tal como señala López Guerra (2002), lo que se produce es, dentro del mantenimiento de esa competencia general, el traslado de algunas funciones (posiblemente las consideradas más delicadas) que ostentaba el poder ejecutivo al Consejo de la Magistratura. Pero el traslado de esas funciones (esencialmente relativas a la designación, promoción, inspección y disciplina de los jueces) se produce mientras que el Ministerio de Justicia mantiene su competencia sobre el grueso de la gestión judicial, en materias como presupuesto, retribuciones, creación de plazas, medios materiales y personal auxiliar (p. 253).

Lo anterior muestra claramente que la intención en el modelo francés e italiano, trasladado al sur de Europa -especialmente a España y a Portugal- y que luego es incorporado en las Constituciones que emergen en los años noventa, busca no solo mantener la independencia y autonomía de los jueces, sino que también intenta estabilizar las expectativas sobre las renacientes democracias. Estas se ciernen como modelos apropiados para encontrar alivio a las tensiones dejadas por la guerra y a los intentos de posicionar partidos políticos con promesas democratizadoras.

Sin embargo, detrás de este modelo, que intenta preservar el poder a través del control por parte del Poder Ejecutivo, está el propósito de mantener la independencia necesaria en el funcionamiento del sistema judicial. De esta manera, se pueden acercar las promesas de realización personal, hechas al ciudadano común, en pro del fortalecimiento de la democracia, mediante una forma de designación de jueces que cumpla con la esperanza de justicia, encarnada en las Constituciones de esa Europa renaciente.

Luego, surge el llamado "modelo americano", que hace énfasis en la legitimidad del nombramiento y en la función independiente y autónoma de jueces y magistrados, a partir de la teoría de separación de poderes, piedra angular, desde Montesquieu, de los regímenes políticos democráticos, sobre todo de aquellos basados en el constitucionalismo filosófico.

Según este, son las Constituciones logradas a partir del fragor de las discusiones políticas y del principio democrático, las que estipulan las reglas sobre 
las cuales se fundan los Estados de Derecho. La idea de este modelo es permear del sentido democrático constitucional la designación de jueces y magistrados, sin que para ello medien intereses más allá del desarrollo del Derecho y de los propios de la República, fundada en este mismo sistema.

Respecto a este modelo, López Guerra (2002) expresa:

Muy distinta ha sido la situación en los países de América Latina. En ellos, la presencia formal del órganos (sic) del poder ejecutivo en la organización de la justicia no ha sido tan destacada como en Europa, debido a la adopción de fórmulas constitucionales más fieles al principio de separación de poderes. En América Latina, en gran manera, la Corte Suprema ha ocupado históricamente el lugar que en Europa correspondía al Ministerio de Justicia (p. 253).

En lo dicho anteriormente se encuentra otra afirmación que no se indica de manera explícita. Ella tiene que ver con que, siendo las Cortes Supremas de los países latinoamericanos los órganos encargados de las funciones del gobierno judicial -y en obediencia a la teoría de la separación de poderes-, se ve claramente que este se encuentra permeado por dicho principio. Esto, toda vez que las Cortes Supremas de los países de América están creadas por vía de las Constituciones, además de estar regladas casi siempre por leyes orgánicas o por la misma Constitución que las crea.

Consecuentemente, la legitimidad de origen de las Cortes Supremas implica la potestad de organizar su propio gobierno, esto es, el de jueces y demás funcionarios judiciales, incluyendo los Consejos de la Magistratura, los cuales, en el otro modelo, son designados por el Poder Ejecutivo. La idea central de la presencia de estos Consejos en el modelo americano, como especie híbrida del europeo, es que sean las Constituciones las que creen, de forma originaria, la competencia de dar a las Cortes Supremas su propio gobierno.

De todo lo anterior, se concluye que el gobierno judicial en Latinoamérica oscila entre el modelo europeo, que parte de la creación de un Consejo especializado, y el modelo americano, que acentúa la legitimidad de este gobierno en la creación por vía constitucional. Lo anterior, conlleva que los Poderes Ejecutivo y Legislativo sean quienes se atribuyan la conformación de la estructura del órgano de gobierno judicial, creado por la misma Constitución, a través del nombramiento de los magistrados de las Cortes Supremas. Tales son los casos de Colombia y Venezuela, siendo precisamente el segundo el que se analiza en este texto. 
Por ello, es fundamental aclarar, antes de entrar en materia, que la justicia como valor en un Estado Democrático de Derecho, no solo se alcanza a través de su legítima administración, esto es, mediante la operatividad de un gobierno judicial que recoja las expectativas ciudadanas, traducidas en el desempeño competente del juez o magistrado.

Más bien, la justicia se alcanza por medio de la conformación de un entramado jurisprudencial que, por intermedio del juez, se traduzca en pluralismo político, el cual se base en la legitimidad de las decisiones y en la incorporación del principio democrático, por vía de las buenas prácticas durante su desempe$\tilde{n} \mathrm{o}^{53}$, garantizadas en principio por la independencia y la autonomía del juez o magistrado.

\section{Un referente necesario}

En Venezuela, particularmente, los movimientos democráticos han luchado infructuosamente, durante décadas, por la reforma integral del sistema judicial, muchas veces logrando pocos o nulos efectos sobre la imparcialidad del mismo, lo cual ha traído consecuencias directas de preferencias hacia el justiciable, debido a las decisiones finalmente tomadas por los jueces seleccionados.

Lo anterior, más allá de las apariencias democráticas presentadas en el historial republicano de los últimos sesenta años. Desde la década del cincuenta, hasta el presente, se han sucedido varios sistemas de administración judicial, traducibles básicamente en tres formas particulares de gobierno, relativas a los dos modelos señalados en el apartado previo. Por un lado está el del Ministro de Justicia, por otro, el del llamado Consejo de la Judicatura y, por último, el que está vigente actualmente, centrado en el poder de designación del propio Tribunal Supremo de Justicia.

El Tribunal es nombrado por un sistema de selección, sustentado en ternas, las cuales son presentadas por los poderes y por los ciudadanos. Esto permite, finalmente, la elección por consenso y conforme a un sistema ante el Poder Legislativo, que se da mediante votación de las dos terceras partes de la 
conformación de la Cámara de Diputados (por derecho conformada por una sola cámara de diputados) $)^{54}$.

Sin embargo, a pesar del esfuerzo involucrado y de la voluntad manifiesta en políticas públicas lógicas y aceptables en la teoría, orientadas a alcanzar un sistema ideal de designación, el panorama no ha cambiado notablemente. En este, la discrecionalidad en los nombramientos de los jueces es una norma que, de facto, ha funcionado como regla general, trayendo como consecuencia cuestionamientos de manera global sobre la legitimidad de las decisiones judiciales, a pesar de las apariencias de legalidad durante el trajín riguroso de la justicia formal, frecuentada en la escogencia de los magistrados a lo largo de esa historia.

En efecto, como indica Louza (2005),

Venezuela ha transitado por diversos sistemas de gobierno judicial a lo largo de los últimos cincuenta años, sin que por ello la situación de la justicia, o cuando menos la percepción pública que de ella se tiene, haya mejorado. Esta apreciación local se ve reforzada por la experiencia internacional, pues existen en el mundo distintos ejemplos de sistemas de administración de justicia exitosos, sin que sea una constante entre ellos el sistema de gobierno judicial elegido (p. 33).

Sin embargo, a pesar de este criterio, la idea de nombramiento de jueces y magistrados ha estado siempre marcada por conflictos políticos, en especial si se trata de aquellos funcionarios con competencia directa en la interpretación de la Constitución. Esto, debido a que la Sala Constitucional del Tribunal Supremo de Justicia tiene las competencias interpretativas del proyecto político de la Carta Magna, que son las que finalmente lo reconstruyen o tergiversan. Por ello, las luchas políticas en torno a la designación siempre tienen que ver con estos conflictos, tal como lo señalan Villalobos y Bozo (2010).

Respecto a estos antagonismos en torno a la Constitución, estos autores afirman:

Los problemas generados desde la perspectiva mencionada, apuntan hacia una dimensión procedimental para la aplicación del derecho constitucional, cuestión que en el pasado y bajo las concepciones conservadoras del derecho, no tenían cabida

54 Es importante señalar que la más reciente designación de magistrados al Tribunal Supremo de Justicia fue desconocida por el Presidente de la República, creando con ello más tensiones políticas sobre el desempeño de la democracia como sistema en Venezuela. Ver reseña periodística del 21 de julio de 2017, en BBC NEWS: https:// www.bbc.com/mundo/noticias-america-latina-40688067. 
en virtud de la rigidez de interpretación por parte del juez constitucional frente a las controversias por los derechos fundamentales (Villalobos \& Bozo, 2010, p. 383).

Así, vemos que los conflictos surgidos a raíz de la interpretación de los derechos fundamentales, comienzan por los criterios de selección de los magistrados del Alto Tribunal, pues son estos quienes finalmente toman las decisiones que van delineando el curso político de la acción social. De allí la importancia de su estudio.

\section{El sistema de nominación en la Ley de Carrera Judicial de 1980 y su Reforma de 1998}

Vistos los fundamentos filosóficos hasta aquí discutidos, ahora se puede considerar el caso concreto señalado, a saber, el sistema de designación de jueces en Venezuela, que se encuentra previsto en diversos cuerpos normativos.

En primer lugar, está la Ley de Carrera Judicial ${ }^{55}$, la cual fue creada con la finalidad de asegurar la idoneidad, estabilidad e independencia de los jueces en su profesión como funcionarios, regulando las condiciones para el ingreso, permanencia y terminación en el ejercicio de la judicatura, así como con el objetivo de establecer la responsabilidad disciplinaria respecto a la realización de sus funciones. No obstante, hay que decir que dicha ley, ciertamente, no es el primer esfuerzo por regular la materia.

La Constitución de 1961 creó el Consejo de la Judicatura, una entidad de carácter autónomo, cuyas funciones -entre otras- eran el gobierno y la administración del poder judicial, al igual que el nombramiento y la remoción de jueces. Pero, este ente empezó a funcionar solo hasta 1969, cuando la Ley Orgánica del Poder Judicial finalmente estableció lo concerniente a su conformación y atribuciones. Más allá de esto, tuvo que esperarse hasta 1980 para que la función judicial contara realmente con un sistema propio para la procedimentalización del poder de judicatura en su ámbito administrativo, a pesar de que la carrera judicial no fue propiamente instaurada como práctica democrática.

Tal como señalan Ayala y Casal (2008),

la razón de ser del Consejo de la Judicatura fue tergiversada por la praxis institucional y el establecimiento de la carrera judicial fue un mandato constitucional incumplido. 
Habría que esperar a 1980 para la promulgación de la Ley de Carrera Judicial, que reguló las distintas etapas de esta carrera, desde la selección e ingreso de los jueces por concurso, pasando por su permanencia y ascenso, hasta llegar a la terminación de la carrera mediante jubilación, sin perjuicio de la posibilidad de destitución en virtud de la comisión de falta grave, previa instrucción del procedimiento correspondiente. Sin embargo, la carrera judicial no fue instaurada y el ingreso de los jueces no se sometía al procedimiento de los concursos (p. 435-499).

El Consejo de la Judicatura nunca fue una institución verdaderamente autónoma e independiente, especialmente en su desempeño, dado que su órgano directivo era seleccionado por las tendencias políticas dominantes. Esta cuestión era de esperarse, pues, como en todo sistema democrático, las tensiones que traía consigo la pugna por el control del poder forzaban muchas veces a acuerdos para la conformación de las estructuras del gobierno judicial. Así, según mandato de la propia Ley Orgánica del Poder Judicial, los nueve magistrados que conformaban el Consejo de la Judicatura eran escogidos de la siguiente manera: cinco por la Sala Político Administrativa de la Corte Suprema de Justicia, dos por el Congreso y dos por el Presidente de la República.

Como señala Damiani (2013),

las buenas intenciones destacadas se vieron anuladas por una razón de peso: los abogados escogidos para formar parte del Consejo de la Judicatura no eran conocidos por su actividad jurídica, sino por su afinidad política, por su lealtad hacia AD y $\mathrm{Copei}^{56}$.

Desde luego que esta fórmula empañó una de las más importantes funciones del Consejo de la Judicatura: la selección y designación de los jueces. De esta forma, aunque este Consejo no pertenecía al Poder Judicial ni realizaba ninguna labor hermenéutica, ni de aplicación del ordenamiento jurídico; era el organismo encargado de la Administración y Gerencia Judicial (pp. 435-499).

Dado que los partidos políticos eran quienes en última instancia seleccionaban a los magistrados del Consejo de la Judicatura, era irrealizable la separación del sistema de justicia de las luchas políticas ${ }^{57}$. Peor aún, el poder judicial se convirtió, en opinión de Quintero (1988), en "una zona de distribución o de

56 Justamente este afán de control del poder colonizó las instituciones políticas del Estado, cuestión que contaminó todas las instancias del poder, alejándose de la perspectiva democrática propiamente dicha. Al respecto, ver Ayala y Casal (2008).

57 Esta cuestión se ha potenciado en los últimos años de vida política en Venezuela, especialmente con el nombramiento de jueces del Máximo Tribunal del país, lo cual ha traído como consecuencia graves conflictos políticos 
acomodación de sus militantes o simpatizantes" (p. 6). De la misma opinión es Pérez Perdomo (1993), quien afirma que el poder judicial y su gobierno se transformaron en lucha de poderes, debido a las pugnas que surgían entre los partidos de gobierno (AD y COPEI, pues los otros que conformaban el espectro político venezolano solo participaban de forma precaria).

Igualmente, el sistema judicial nacional había sido objeto de numerosas críticas, tanto nacionales como internacionales. El Informe del Lawyer's Committee for Human Rights de 1996, señaló que,

en lugar de cumplir el papel constitucional de garantes del Estado de Derecho y protectores de los derechos humanos de los ciudadanos venezolanos frente al gobierno, los tribunales se transformaron con frecuencia en adjuntos políticos de los partidos. Eran manipulados por grupos de abogados, jueces, actores políticos y empresariales para su beneficio económico. Y los procedimientos judiciales se habían vuelto tan lentos, enrevesados y poco fiables que los demandantes los evitaban a toda costa.

Sin embargo, es preciso mencionar que tal situación era endémica en Latinoamérica, donde el autoritarismo y la corrupción habían negado a los tribunales la total independencia, de plano inexistente o viciada, haciendo de las propias magistraturas el lugar en el que empezaba dicho abuso del poder, de manera sistemática. Como indica Mergal (1997),

los diagnósticos administrativos muestran que la administración judicial ha sido tradicionalmente y en la mayor parte de los países obsoleta, alejada de las prácticas básicas de administración, sin recursos técnicos suficientes, en exceso centralizada, sin elementos profesionales, sin programas de carrera, ni especialización (p. 1).

Entonces, se hizo indispensable una reforma del sistema, que debía iniciar con la creación de un marco normativo para el ejercicio de la función judicial. El primer paso hacia ese objetivo se dio con la Ley de Carrera Judicial de 1998. En dicho cuerpo normativo se introdujo, por primera vez, el escalafón judicial para el ascenso de los jueces, el cual permitiría a dichos funcionarios pasar progresivamente por las diversas categorías existentes en la circunscripción a la que pertenecían, acumulando para ello tiempo, méritos y credenciales, todo lo necesario para el tránsito por la carrera judicial.

reseñados por la historia reciente, incluso con repercusiones en el ámbito político internacional. Ver: Diario Las Américas del 23 de diciembre de 2015. 
Así, al distribuirse de manera jerárquica y vertical la competencia de los tribunales y de los jueces, y al establecerse el ascenso de acuerdo con los años transcurridos en el ejercicio de las funciones, así como con las credenciales y méritos acumulados, se garantizaba que los administradores de justicia estuvieran en constante crecimiento profesional y ejercieran su cargo de manera loable, correcta, idónea, imparcial, expedita y en estricta observancia de los principios y garantías constitucionales.

En otras palabras, el telos de la Ley de Carrera Judicial era el de aspirar a servir de garantía para los justiciables, haciendo que los jueces estuvieran capacitados para ejercer la labor jurisdiccional $\mathrm{y}$, sobre todo, que cumplieran los requisitos exigidos para ostentar tales cargos públicos.

Estos requisitos, de acuerdo con las principales teorías ${ }^{58}$ que se esgrimen en este trabajo, son de gran importancia en el desarrollo de todo sistema democrático, ya que de estos depende la búsqueda de la justicia como el valor supremo que rige todo Estado de Derecho, y como fin último de todo proceso judicial en el marco de dicho sistema. Además, siguiendo a Habermas (1997), establecen que la democracia debe ser regida por el derecho formal.

Por otro lado, además de lo relativo a la preparación y aptitud de los jueces, estaba la cuestión de su independencia en un sentido directo, es decir, de su libertad (ostentada por definición) para decidir, sin temor a represalias, lo que implicaba no estar sujetos a presiones internas o externas en el ejercicio de sus funciones. Esta independencia debía protegerse desde el mismo momento del nombramiento como juez, ya que de esto dependía la garantía de las buenas prácticas judiciales, pues, como ha señalado la Comisión Interamericana de Derechos Humanos (2009), "un adecuado proceso de designación de los miembros del poder judicial, que sea transparente y garantice la igualdad de los candidatos, es garantía fundamental para su independencia" (p. 187).

Si bien es evidente que los mecanismos para la escogencia de jueces tenían que estar claros y conformes con reglas democráticas, estos también debían ser seleccionados con miras a garantizar su independencia. En este sentido, era la

58 Como las de Habermas (1997 y 1998); las de Norberto Bobbio, en Estado, gobierno y sociedad (2016); y las de Giovanni Sartori, en La democracia en 30 lecciones (2009). En estos autores está la idea de que la democracia es un sistema complejo, dentro del cual coexisten diversos aspectos que desarrollan su siempre buscado desempeño, por lo que se agrega que el ejercicio de los derechos y su operabilidad le son necesarios. 
norma la que debía considerar cuál era el mecanismo idóneo, no solo para este fin, sino también para asegurar la excelencia de los escogidos.

De modo tal que el artículo 10 de la Ley de Carrera Judicial, consagró el requisito de impretermitible concurrencia, que debía cumplir todo ciudadano que optase al cargo de juez en Venezuela ${ }^{59}$. Lo que se desprendió de esta norma fue que el ingreso a la Carrera Judicial se debía llevar a cabo mediante concurso de oposición, siendo necesario que el postulante cumpliera con los requerimientos allí establecidos.

Adicionalmente, el legislador previó la necesidad de crear una institución para la preparación de jueces y funcionarios tribunalicios. La Ley de Carrera Judicial, reformada en 1998, instauró la Escuela de la Judicatura. En su análisis exegético de la norma, Vilera (2009) señala:

Para contribuir en la búsqueda y selección del más apto se había creado la Escuela de la Judicatura que tendría como tarea fundamental la de "lograr la mejor capacitación teórica y práctica tanto de los aspirantes a ingresar a la carrera judicial como la de los jueces en ejercicio de sus funciones" (artículo 68 de la Ley de Carrera Judicial, artículo 48 de la ley de carrera judicial de 1998). Para alcanzar estos objetivos la Escuela de la Judicatura debería organizar y ejecutar los cursos correspondientes, pues, como ya quedó dicho, por norma expresa (artículo 14 Ley de Carrera Judicial, modificado por la ley de 1998, parte de su contenido integra el artículo 10 de esta norma) se dejó establecida la aprobación de dichos cursos como requisito para el ingreso a la carrera judicial (p. 20).

Sin embargo, la Escuela de la Judicatura nunca, ni siquiera en sus primeros años, cumplió el rol que el legislador tenía previsto para ella, ya que ninguno de los cientos de egresados de esta institución fue llamado a ingresar al Poder Judicial (Quijada, 1998).

59 Este artículo dispone condiciones curriculares y éticas mínimas indispensables para ingresar a la Carrera Judicial. En este sentido, básicamente se necesita la aprobación de un concurso de oposición, con la mayor calificación y que el candidato sea declarado apto psicológicamente. A estas condiciones concurren asimismo otras de tipo ético (conducta intachable), sumadas a: ser mayor de veinticinco años de edad, no estar inhabilitado políticamente y tener una experiencia profesional comprobada de tres años como mínimo, o tener como equivalente postgrado en materia jurídica.

La misma normativa regula integralmente el ingreso a la Carrera, basada en el escalafón judicial. De esta manera, se presentan varias categorías, ingresando primero con la que corresponde a la "C". También pueden ingresar y ser admitidos a concurso en las categorías "A" y "B" aquellos aspirantes, mayores de treinta años, distinguidos en su especialidad jurídica, que sean autores de trabajos jurídicos valiosos o profesores universitarios de reconocida trayectoria, tanto abogados con una experiencia forense comprobada de diez años, como funcionarios públicos -defensores o fiscales del Ministerio Público- con no menos de seis años de servicio. 
El artículo 18 de la Ley de Carrera Judicial estableció una normativa basada en la meritocracia, en el sentido de que el Consejo de la Judicatura debía designar como juez titular del tribunal al participante que obtuviera la mayor calificación en el concurso de oposición. Lo anterior, dentro de la escala de puntuación comprendida entre un mínimo de las tres cuartas partes del total de puntos establecidos para el concurso. Así mismo, los aspirantes que hubieran obtenido el segundo y tercer puesto en la mencionada escala de puntuación, debían ser designados, respectivamente, como primer y segundo suplente del titular.

En dicha ley se precisó que el Consejo de la Judicatura, por necesidades del servicio, asignase dichos suplentes a cualquier tribunal de la misma categoría y especialidad de aquel para el que concursaban los aspirantes. De igual manera, el concurso de oposición podía ser declarado desierto si los concursantes obtenían calificaciones inferiores al mínimo de las tres cuartas partes del total de puntos establecidos. Ello se previó en aras de garantizar que los jueces del país fuesen personas altamente calificadas, en virtud de la trascendencia de la función que debían realizar ${ }^{60}$.

De la misma manera, el artículo 21 de la Ley analizada dispuso que la provisión de los cargos vacantes y de los que se creasen conforme a la Ley, tenían preferencia en función de un orden de prelación basado en la Carrera Judicial.

Se puntualizó, además, todo un sistema basado en la meritocracia, de manera tal que los jueces, por concurso, ascenderían en el escalafón, hasta la categoría inmediatamente superior, según méritos alcanzados, el tiempo de servicio que tuviesen en la categoría previa y la aprobación de los exámenes selectivos organizados por el Consejo de la Judicatura. Los jueces que no hubiesen aprobado, no podían ascender.

En cuanto a los ascensos en la Carrera, se harían previa calificación de méritos de los jueces de la misma categoría. La evaluación se dispondría en un lapso

60 Asimismo, la referida norma dispone que los suplentes designados deben llenar las faltas temporales y accidentales del juez titular. Empero, cuando por cualquier motivo no sea posible la designación de suplentes con arreglo a lo previsto en el artículo 18 de la Ley de Carrera Judicial, el Consejo de la Judicatura debe proveer el cargo a un abogado que reúna las condiciones exigidas en el artículo 10 eiusdem. Si no lo hubiere, entonces este puede corresponder a personas idóneas conforme a la ley. Los suplentes tienen su función hasta que tome posesión el nuevo titular designado mediante concurso, lo cual debe realizarse dentro de los tres meses siguientes a la fecha de la vacante. El juez suplente puede participar en él. Debe hacerse la salvedad de que para la provisión de los cargos de juez titular y de suplentes de la Jurisdicción Penal se prefiere, en igualdad de circunstancias, a aquellos concursantes que sean defensores públicos o fiscales del Ministerio Público, con más de cinco años de ejercicio en la función correspondiente. 
no mayor de sesenta días continuos, a partir de la fecha en que se produjera la vacante o se creara el nuevo cargo. La convocatoria a las pruebas selectivas para la promoción a una categoría superior se haría por el Consejo de la Judicatura, cada vez que existieran cargos vacantes o se crearan otros nuevos.

Es importante indicar que, conforme lo establecía el artículo 31 de la Ley de Carrera Judicial, el rendimiento de los jueces era evaluado, periódicamente, por el Consejo de la Judicatura. Y, para ello, dicho organismo debía tomar en consideración diferentes elementos o variables, entre los que se encontraban criterios cuantitativos y cualitativos. Entre los primeros, estaban: el número de sentencias definitivas o interlocutorias, de casos resueltos y en tramitación, de procesos paralizados y sus causas, de sentencias dictadas, definitivas o interlocutorias y de audiencias o días de despacho por mes. Entre los segundos, estaban: la ausencia de sanciones y la emanación de sentencias en el plazo o término legal.

Por consiguiente, si al realizarse la evaluación anual el rendimiento del juez no era satisfactorio, el Consejo de la Judicatura debía proceder de inmediato a separarlo de la Carrera Judicial y a convocar el correspondiente concurso de oposición. La excepción a esto se daba si existían causas que justificaran claramente las razones o los hechos que hubiesen podido motivar el bajo rendimiento del funcionario.

Por otra parte, la Ley en cuestión señalaba que los concursos debían ser públicos y que su notificación debía hacerse, por lo menos, con diez días de anticipación a la fecha fijada para su celebración, en un diario de circulación regional, indicando el día, la hora y el lugar donde se habría de realizar. El concurso constaba de tres pruebas: una de credenciales y de méritos; una escrita, de carácter práctico; y una oral, de carácter teórico.

El Consejo de la Judicatura, en caso de que el concurso resultara desierto, debía convocar a uno nuevo. Si esto ocurría por segunda vez, procedía a la provisión del cargo a un juez interino, que reuniera las condiciones exigidas en el artículo 10 de la ley en cuestión, hasta que la designación se pudiera realizar a través de otro concurso, el cual debía ser convocado en un lapso no mayor a seis meses. 


\section{El actual sistema de nominación de jueces en Venezuela, en la Constitución de 1999}

A pesar de lo analizado en el apartado anterior, la Constitución de la República Bolivariana de Venezuela (1999), en el Título V. De la Organización del Poder Público Nacional, Capitulo III. Del Poder Judicial y del Sistema de Justicia, y en correspondencia con la Ley de Carrera Judicial, establece expresamente que el ingreso y el ascenso de los jueces en dicha carrera debe ser mediante concursos de oposición públicos. Esto, de conformidad con lo pautado en el artículo 255 del texto constitucional, norma clave para el régimen del Poder Judicial ${ }^{61}$.

Así, se introduce en la Constitución venezolana la figura de la participación ciudadana en el procedimiento de selección y designación de jueces, específicamente en el artículo 253, en el que se prevé que "la potestad de administrar justicia emana de los ciudadanos y ciudadanas y se imparte en nombre de la República por autoridad de la ley". De la misma manera, en el artículo 261, se señala que los jueces de la jurisdicción penal militar forman parte integrante del Poder Judicial, por lo que también deben ser seleccionados a través de concurso. Ahora bien, la Constitución no señala los requisitos para ser juez. Estos, como se indicó en líneas anteriores, se encuentran previstos en el artículo 10 de la Ley de Carrera Judicial de 1998.

Más allá de las reformas realizadas a la Constitución Nacional, el Poder Judicial, en el nuevo milenio, se encuentra en una posición no muy diferente a la

61 De acuerdo al artículo 255, el ingreso a la carrera judicial, y el ascenso de los jueces o juezas, debe hacerse por concursos de oposición públicos, que aseguren la idoneidad y excelencia de los o las participantes, quienes serán seleccionados o seleccionadas por los jurados de los circuitos judiciales, en la forma y condiciones que establezca la ley. En este sentido, el nombramiento y juramento de los jueces corresponde al Máximo Tribunal de Justicia. Seguidamente, corresponde a la ley desarrollar los postulados o principios para la participación ciudadana en el procedimiento de selección y designación de los jueces.

Con esta norma se han querido garantizar los derechos de participación ciudadana, dentro del paradigma del modelo de la democracia participativa y protagónica, de la Constitución de 1999. Asimismo, se garantiza la carrera y la estabilidad judicial, cuando se decreta que los jueces solo pueden ser removidos(as) o suspendidos(as) de sus cargos mediante los procedimientos disciplinarios expresamente previstos en la ley. Seguidamente, se garantiza la Carrera Judicial, al indicarse que la ley debe propender a la profesionalización de los jueces, cuestión en la que deben colaborar las universidades, abriendo en la carrera jurídica los ámbitos de la especialización judicial.

Por otra parte, la responsabilidad personal del juez, por actuaciones culposas, es una innovación jurídica, derivada de la normativa constitucional, donde se establece la justicia como servicio público. En este sentido, los jueces son personalmente responsables, en los términos que determine la ley, por error, retardo u omisión injustificada; por la inobservancia sustancial de las normas procesales; por denegación y parcialidad; y por los delitos de cohecho y prevaricación en que incurran en el desempeño de sus funciones. 
que había tenido en décadas previas, y por la que fue considerado como "corrupto, ineficiente, poco confiable, clasista, parcializado, remoto y mediatizado por presiones de todo tipo" (Roche, Richter \& Pérez, 2002, p. 209).

Pese a la vigencia de la Ley de Carrera Judicial, la cual no ha sido derogada como exige el artículo 218 de la Constitución Nacional-, el Tribunal Supremo de Justicia, en Sala Plena, en ejercicio de las atribuciones conferidas por el artículo 17 de la Ley Orgánica, en concordancia con la Resolución No 2004-0012 del 18 de octubre de 2004, dicta las Normas de evaluación y concurso de oposición para el ingreso y ascenso a la carrera judicial ${ }^{62}$.

Dentro de este marco jurídico, el Tribunal Supremo de Justicia establece que las referidas normas tienen por objeto la regulación de la Carrera Judicial (ingreso, ascenso y permanencia), mediante los concursos públicos de oposición y las evaluaciones de desempeño, de conformidad con el artículo 255 de la Constitución venezolana. Esto, sin perjuicio de las regulaciones que a tal efecto dicta la Sala Plena del Tribunal Supremo de Justicia y de los instrumentos que sirven para la evaluación y capacitación de los demás servidores del Poder Judicial.

De esto se desprende todo un sistema administrativo de planificación de la Carrera Judicial, bajo la égida de la Escuela Nacional de la Magistratura, la cual debe planear, supervisar y ejecutar todas las actividades relativas a los concursos públicos de oposición, así como las relativas a la evaluación de los jueces y demás servidores del Poder Judicial. En este contexto, la Escuela debe llevar un expediente de cada juez o aspirante a la Carrera Judicial, que contenga sus datos personales y toda aquella información que permita evaluar su rendimiento y conducta.

Asimismo, en el artículo 3 de las Normas se establece que para la conformación del expediente, la Escuela Nacional de la Magistratura debe racionalizar sus sistemas y métodos de trabajo, mediante la adopción de medidas y procedimientos más idóneos, para lo que podría requerir la información de cualquier persona natural o jurídica, pública o privada, nacional o extranjera, sin perjuicio de que el interesado aporte al expediente los documentos requeridos.

El ingreso a la Carrera Judicial solo puede efectuarse por concurso público, fundamentado en los principios de honestidad, idoneidad y eficiencia. Este incluye la aprobación de los programas de formación inicial, la evaluación médica y psicológica y el examen de conocimientos. 
Por su parte, el ascenso está sometido a métodos basados en el sistema de méritos, antigüedad y cargo vacante. Se puntualiza que el Tribunal Supremo de Justicia, por órgano de la Escuela Nacional de la Magistratura, con el objetivo de garantizar la debida difusión, llama a concurso mediante avisos publicados en dos de los diarios de mayor circulación nacional, en uno de circulación regional, según sea el caso, y en la página web del Tribunal ${ }^{63}$.

A fin de que esto sea del conocimiento de los interesados, así como de que se pueda garantizar el control social a través de la participación ciudadana, la Escuela Nacional debe publicar oportunamente, en diversos mecanismos de información, las actividades relacionadas con la celebración del Concurso Público, tales como la preinscripción, admisión e inscripción en los programas desarrollados por la misma. Además, debe hacer un listado nacional de los jurados con el lugar, la fecha y la hora de celebración del examen de conocimientos.

Como consecuencia de lo anterior, las Normas de evaluación y concurso de oposición para el ingreso y ascenso a la Carrera Judicial ${ }^{64}$, han sustituido la antigua Ley de Carrera Judicial. Sin embargo, en esta última se ha mantenido el concurso de oposición para optar por el cargo de juez en la República Bolivariana de Venezuela.

Precisamente, en las Normas de evaluación y concurso se pueden observar ciertas innovaciones. Entre ellas hay una que se refiere específicamente a la notificación del concurso. Esta ya no se debe realizar con diez días, por lo menos, de anticipación a la fecha fijada para su celebración, en un diario de circulación regional, indicando el día, la hora y el lugar donde se ha de realizar el evento. En cambio, ahora esto debe hacerse mediante avisos publicados en dos de los diarios de mayor circulación nacional, en uno de circulación regional (según sea el caso), y en la página web del Tribunal Supremo de Justicia.

De este modelo de selección de jueces se concluye que la intencionalidad del Tribunal Supremo de Justicia es, aparentemente, garantizar la participación ciudadana establecida constitucionalmente. Asimismo, en este se incluye un nuevo requisito formal para optar al cargo de juez, que es la aprobación de los programas de formación inicial.

63 En este aviso se indican los requisitos y lapsos para las inscripciones, la o las categorías y circunscripciones para las cuales se concursa, el número de plazas disponibles, los programas y cualquier otra información que se considere conveniente.

64 Publicadas en Gaceta Oficial №38.282, el 28 de septiembre de 2005, y dictadas por la Sala Plena del Tribunal Supremo de Justicia. 
Por otro lado, y siguiendo la línea de argumentación del presente estudio, se han ampliado los requisitos para el ingreso a la carrera judicial. Entre otros aspectos, en la norma precedentemente citada se incluye como requisito, y consecuente obligación, por parte de quien aspira al cargo de juez, que se abstenga expresamente de realizar activismo político, partidista, sindical o gremial, así como que no esté afiliado a partidos políticos al tomar posesión del cargo. Esta norma, cabe decir, ha sido de larga trayectoria en la tradición democrática republicana, sin embargo, ha sido solapada por la manera en la que, en años recientes, se ha dado realmente la práctica de elegir los jueces.

En ese orden de ideas, también se ha actualizado el escalafón judicial para el ascenso de los jueces, el cual se encontraba desfasado de una real repartición de los tribunales en el país. En tal sentido, se ha determinado que dicho escalafón debe comprender tres categorías: la "C", conformada por los Tribunales o Juzgados del Municipio; la "B", en la que están los Tribunales o Juzgados de Primera Instancia; y la "A", de la cual hacen parte los Juzgados Superiores o Cortes de Apelaciones.

De esta manera, se constata que en las Normas de evaluación y concurso de oposición para el ingreso y ascenso a la Carrera Judicial del 2005, se toma en consideración el cargo por el que se pretende optar. Así, dada la distribución de la competencia de cada juzgado de manera jerárquica, son mayores los requisitos a cumplir para los jueces de rangos superiores. También se explica, de forma detallada, cada trámite a cumplir para tales efectos, así como el procedimiento respectivo.

Otro aspecto de gran importancia, previsto en las aludidas normas, son las disposiciones transitorias, en las cuales se determina la regularización de la titularidad de los jueces provisorios. Dentro de este marco se precisa, en el artículo $46^{65}$,

65 En el artículo 46 de las Normas de evaluación y concurso de oposición para el ingreso y ascenso a la Carrera Judicial, se establece:

A los efectos de regular la situación de los Jueces no titulares, la Sala Plena del Tribunal Supremo de Justicia en fecha 6 de abril de 2005, aprobó el proyecto de normas presentado por la Escuela Nacional de la Magistratura, que incluye el Programa Especial para la Regularización de la Titularidad (PET); conformado por un Programa Académico de Capacitación, evaluación médica y psicológica, evaluación de desempeño, y el correspondiente examen de conocimiento, todo de acuerdo con lo previsto en la presente normativa. El referido programa tendrá una vigencia de doce meses contados a partir de la aprobación por la Sala Plena del Tribunal Supremo de Justicia de las presentes normas. En este caso, aquellos jueces que, para la fecha en que cese la vigencia de dicho Programa, mantengan la condición de Provisorios, Temporales o Accidentales, y no tengan al menos tres (3) meses en el ejercicio de sus funciones judiciales, deberán participar y aprobar el Programa de Formación Inicial (PFI) para obtener la titularidad (Tribunal Supremo de Justicia, Sala Plena, 2005). 
que la Escuela Nacional de la Magistratura debe convocar a concurso solo a aquellos jueces no titulares que, para la fecha de inicio del Programa Académico de Capacitación, tengan al menos tres meses en el ejercicio de la función judicial.

Con posterioridad al cumplimiento del Programa Especial para la Regularización de la Titularidad (PET), la Escuela Nacional debe convocar al Concurso por Ascenso. Con el objeto de regular esta situación, se establece la obligación, para los jueces provisorios, de realizar el Programa Académico de Capacitación y presentar las pruebas respectivas.

Asimismo, se establece el procedimiento para optar a la titularidad, indicando las pruebas que se han de realizar a los jueces, la puntuación que estos deben obtener a fin de ganar el concurso y los aspectos que se estiman en caso de que dos o más concursantes tengan la misma puntuación. Además, se precisa la manera en la que se debe constituir el jurado, así como la necesidad de publicar una lista, en los diarios de mayor circulación nacional y/o regional -además de la página web del Tribunal Supremo de Justicia de la Escuela Nacional de la Magistratura-, con los nombres de quienes hacen parte del mismo, a fin de que la comunidad formule sus observaciones.

Por otro lado, se especifica que, a efecto de la obtención de la titularidad, se debe examinar el desempeño del juez provisorio, con el propósito de apreciar su rendimiento en las labores judiciales, su actitud y comportamiento personal, y demás cualidades requeridas para el buen ejercicio de la función pública judicial. Al mismo tiempo, se precisa que la evaluación del rendimiento del juez y de los factores indicados se efectúe mediante métodos estadísticos, inspección del tribunal, revisión del expediente personal, examen médico y auditoría de cuentas, según estos resulten apropiados a la naturaleza de cada factor.

\section{Crisis del sistema judicial venezolano}

El Tribunal Supremo de Justicia se ha percatado de la crisis existente en el sistema judicial venezolano, donde desde hace más de diez años la mayoría de los jueces han sido provisorios, siendo pocos los titulares escogidos por concurso público. Sin embargo, la Sala Plena del Tribunal, para tener el control y monopolio 
de los funcionarios judiciales, dicta las Nuevas normas de evaluación y concurso de oposición para el ingreso y ascenso a la Carrera Judicial ${ }^{66}$.

En ellas se puntualiza que la Sala Plena del Tribunal Supremo de Justicia, por órgano de su Comisión Judicial, debe ejercer la Rectoría en materia de función judicial. Es importante destacar que la figura de dicha Comisión es extraña a la Constitución de 1999. Al respecto, Pérez Perdomo (2006) expresa:

La Constitución (Artículo 267) previó la existencia de un órgano semi autónomo dentro del Tribunal Supremo denominado Dirección Ejecutiva de la Magistratura. Previó también la existencia de una jurisdicción disciplinaria judicial. En la práctica el Tribunal Supremo estableció un grupo de Magistrados, no previsto en la Constitución, denominada la Comisión Judicial, a la cual subordinó completamente la Dirección Ejecutiva de la Magistratura. En resumen, son los Magistrados que integran la Comisión Judicial quienes tienen un control completo sobre los Jueces (p. 18).

Es decir, a la Comisión Judicial, como órgano competente del Tribunal Supremo de Justica, hoy le corresponde regular el ingreso, ascenso y permanencia en la Carrera Judicial, mediante los concursos públicos de oposición y las evaluaciones de desempeño. En las normas se mantiene in examine el ingreso mediante concursos de oposición públicos y se instituye, al menos nominalmente, que los jueces de la República gozan de estabilidad en el ejercicio de sus funciones. Sin embargo, estos pueden ser suspendidos o destituidos de sus cargos por las causales legalmente establecidas y por los procedimientos previstos en el Código de Ética del Juez Venezolano ${ }^{67}$.

66 Publicadas en Gaceta Oficial № 40.972, el 23 de septiembre de 2016, siendo derogadas, en consecuencia, las Normas de evaluación y concurso de oposición para el ingreso y ascenso a la Carrera Judicial, publicadas en Gaceta Oficial No38.282, el 28 de septiembre de 2005.

67 En el artículo 9 se señalan las diversas fases en las que se debe desarrollar el concurso de oposición, básicamente a través de una convocatoria pública, a cargo de la Comisión Judicial del Tribunal Supremo de Justicia, mediante el portal web Gaceta Oficial y un diario de circulación nacional. Esto, con la presentación, por parte de los aspirantes, de la solicitud de inscripción y de los requisitos establecidos legamente, con la designación del jurado evaluador. Seguidamente, se realiza la evaluación de elegibles, la notificación de los seleccionados, la entrega del temario y, finalmente, la presentación de un conjunto de pruebas de conocimiento y aptitudes, entre las que está la psicológica, la psicotécnica y la médica general. Una vez realizada la evaluación del jurado y la publicación del listado de los seleccionados como jueces para el período de prueba, viene una fase de participación popular e impugnación, así como un tiempo de observación y un curso del programa de formación, con la notificación del nombramiento como jueces titulares y su juramentación. 
Se precisa, además, que la Comisión Judicial del Tribunal Supremo de Justicia debe llevar un expediente de cada participante y llamar a concurso público por circunscripción judicial y por materia. En la convocatoria se indican los cargos vacantes, el circuito judicial del cual forma parte, los requisitos a consignar, los lapsos correspondientes a cada fase, el lugar para las inscripciones y cualquier otra información importante.

Se determina también, como propuesta de la Comisión Judicial, que la Sala Plena del Tribunal Supremo de Justicia es la encargada de conformar una lista nacional de jurados principales y suplentes para la evaluación de los respectivos concursos de oposición públicos. No obstante, la Sala Plena, por órgano de la Comisión Judicial y por motivos justificados, puede modificar dicha lista.

El jurado para cada concurso debe estar conformado por cinco miembros principales, con sus suplentes, de la siguiente manera: por una parte, dos magistrados del Tribunal Supremo de Justicia, uno de los cuales es designado por la Sala Plena y otro que es escogido de la Lista Nacional de Jurados; por otra parte, un profesor de un órgano oficial de formación judicial, designado por la Comisión Judicial del Tribunal Supremo de Justicia; y, finalmente, un miembro del Poder Popular, escogido por la Sala Plena. Los miembros suplentes deben ser elegidos de la misma forma que los principales.

También se indica que los miembros del jurado deben mantener la confidencialidad de las opiniones emitidas en las reuniones, al igual que existe la posibilidad de que estos sean recusados en caso de encontrarse inmersos en alguna de las causales previstas en el artículo 18 de las Normas de evaluación y concurso de oposición para el ingreso y ascenso a la Carrera Judicial.

En el artículo 26 de dichas normas se establece que la evaluación del jurado tiene que realizarse en dos etapas: la primera, es la referida a la evaluación de conocimiento, a través de preguntas formuladas por el jurado (de manera escrita y verbal), en relación con la materia objeto del concurso; y la segunda, es la referida a la evaluación de política judicial, entre otros temas.

Una vez concluidas las evaluaciones, el jurado celebra una reunión final en la que se determina la manera en que deben ser cubiertas las vacantes, conforme a la puntuación obtenida por cada participante. Después de esto, se procede a publicar la lista con los nombres de los designados como jueces, quienes están sometidos a un período de prueba de seis meses. Finalmente, luego de superado 
ese lapso en el que estos son considerados como jueces provisorios, adquieren la titularidad definitiva.

La juramentación de los jueces se hace ante la Sala Plena, la cual delega sus funciones en los distintos circuitos judiciales. De igual manera, su ascenso se realiza mediante concursos de oposición pública, y se señalan las fases del concurso y los requisitos que deben cumplir para ello.

Además de las severas críticas al poder excesivo de la Comisión Judicial, también se señala que,

entre los principios que deben regir los concursos de oposición de acuerdo con el artículo 6, nos encontramos con el de igualdad de trato "sin privilegios de ninguna clase", lo que no se cumple al establecer la Disposición Transitoria Primera que se hará "Concurso de Oposición Público a ser convocado de inmediato para los jueces y juezas activos". Con ello se privilegia a un grupo de personas que no se sometieron para su nombramiento a requisitos ni a procedimientos previos, excluyendo a otros ciudadanos que podrían tener mayores cualidades para el ejercicio de la magistratura. En el mismo sentido, se viola el principio de igualdad ante la ley cuando se prohíbe que personas que hayan participado en agrupaciones o asociaciones que hayan recibido fondos de empresas nacionales participen como jurados, lo que no ocurre si esas agrupaciones reciben fondos del Estado (Observatorio Venezolano de Justicia, 2016, p. 1 )

La Sala Plena del Tribunal Supremo de Justicia ha aprobado las normas que regulan y organizan el ingreso, ascenso y permanencia en la carrera de los jueces de la República Bolivariana de Venezuela, mediante los concursos de oposición públicos y las evaluaciones de desempeño, al tiempo que ha dispuesto un proceso específico de concurso para la regularización de aquellos jueces provisorios o no titulares. Si bien esto es cierto, no debe olvidarse que para ello deben seguirse los cronogramas y las bases de las convocatorias que ha de conocer la Comisión Judicial del Máximo Tribunal.

En este orden de ideas, es forzoso señalar que la realización de los concursos de oposición depende de que se dicten normas sobre el tema, puesto que ya en el $2005^{68}$ se prescribieron ciertos lineamientos que no fueron ejecutados. Por consiguiente, nada asegura el cumplimiento de las nuevas Normas de evaluación y concurso de oposición para el ingreso y ascenso a la Carrera Judicial. 
En este tenor, resulta ineludible indicar que en Venezuela la mayor parte de los jueces tienen el carácter de provisorios, pues desde hace más de doce años no se realizan concursos públicos de oposición, a pesar de que en la Ley de Carrera Judicial se establece esta modalidad como la idónea para ingresar al sistema judicial. A lo anterior debe adicionarse que, hasta ahora, los nombramientos de jueces provisorios son totalmente discrecionales por parte de la Comisión Judicial, sin el previo cumplimiento de los requisitos señalados con anterioridad y sin el correspondiente proceso de selección.

La ONG Human Rights Watch (2014) se ha referido a los jueces provisorios en Venezuela como jueces "desechables" a quienes se les ha negado la estabilidad laboral, una de las salvaguardas fundamentales de la majestad e independencia judicial. Esto quiere decir que con la misma facilidad con la que son nombrados pueden ser destituidos discrecionalmente, sin que se expresen las razones de tal decisión. Ello vulnera el principio de la Carrera Judicial e impide el cumplimiento de los estándares internacionales exigidos para la función judicial (estabilidad en el cargo, procedimiento previo para ser destituido o suspendido, etc.). De esta manera, se infringe el artículo 5 de las Normas de evaluación y concurso de oposición para el ingreso y ascenso a la Carrera Judicial y demás leyes de la República, lo cual se traduce en falta de independencia y autonomía administrativa y funcional.

\section{Críticas al modelo basado en la Comisión Judicial del Tribunal Supremo de Justicia, no previsto en la Constitución de 1999}

Anteriormente se ha afirmado que el modelo ad hoc que rige el gobierno judicial en Venezuela está basado en una Comisión Judicial, creada en las Normas de 2005 y ratificada en las Normas de 2016. Sin embargo, han sido múltiples las críticas realizadas a los intentos, por parte del Tribunal, de instaurar en la práctica un régimen de gobierno judicial, apegado a estas últimas Normas. Entre dichas críticas pueden mencionarse las siguientes:

1. Las normas no establecen la obligación de que el Tribunal Supremo realice un cronograma o planificación que permita saber cuánto tardará en cumplir con su deber de establecer un Poder Judicial, con el cien por ciento de los jueces nombrados mediante concursos de oposición. 
2. Las normas otorgan a la Comisión Judicial un poder exorbitante y discrecional, al punto que le permiten cambiar decisiones del órgano que la designa, es decir, de la Sala Plena, lo cual viola el principio de jerarquía.

3. A pesar de que uno de los requisitos para ser juez es no realizar activismo político, entre los jurados está un representante del poder popular, que por definición está comprometido con el proyecto ideológico partidario del socialismo del siglo xxi en Venezuela. De acuerdo a la ley que lo regula, este tiene como finalidad "construir las bases de la sociedad socialista" (art. 7), lo que pone en evidencia otra grave contradicción respecto a los principios de imparcialidad e independencia previstos en la Constitución.

4. Las normas no establecen un plazo máximo de duración de los concursos, ni tampoco los lapsos para el cumplimiento de cada una de sus fases, pues se dejan al arbitrio de la Comisión Judicial.

5. Las normas afirman que los concursos se rigen por la igualdad de trato ante la ley, pero este principio se viola al permitir que la Comisión Judicial establezca concursos de oposición solo para los jueces provisionales.

6. Se mantiene la potestad de la Comisión Judicial de nombrar jueces provisorios, con independencia de la realización de los concursos de oposición, con lo que se mantiene el nombramiento discrecional de jueces sin procedimiento, requisitos previos, ni estabilidad alguna.

Puede afirmarse que es inevitable que haya jueces provisorios, puesto que pueden ocurrir faltas absolutas de dichos funcionarios, quienes no pueden ser sustituidos rápidamente mediante un concurso de oposición. Sin embargo, no debe olvidarse que en las normas aludidas se establecen diversas posibilidades frente a dicha situación, entre ellas, que se puedan designar a los suplentes de acuerdo con los resultados de los concursos o que se siga el escalafón de los que no quedaron en el mismo, mientras se llama al siguiente concurso. En consecuencia, es falso que la única manera de equilibrar la precariedad de los jueces temporales sea mediante un nombramiento sin procedimiento ni requisitos por parte de la Comisión Judicial.

En la práctica, según afirma Duque Corredor (2005), la Comisión ha pasado a convertirse en el instrumento del poder político, o del gobierno de turno, para ejercer presión e influencia sobre los jueces, dado que esta no solo puede 
nombrar a los provisorios, sino que también puede destituirlos. Esto implica que tales jueces carecen de estabilidad, requisito imprescindible para la independencia judicial.

Siguiendo la argumentación y crítica sobre la referida normativa, se tiene que:

1. Las normas establecen un complejo proceso en fases, sin estipularse lapsos para ninguna de ellas, de modo que esto queda a discreción de la Comisión.

2. Respecto a la evaluación, no se establece un baremo previo que determine las reglas y valores de la misma, es decir, que permita calificar a los que aplican al concurso. Sin embargo, el único que aparece es el que debe ser aplicado con fines de generar el listado de seleccionados para participar en el mismo.

3. Una vez el jurado toma la decisión, la Comisión Judicial debe publicar la lista de los seleccionados (art. 28) y, a partir de ello, "se ejercerá control social" (art. 29) mediante la consignación de observaciones y objeciones, así como de los soportes que las sustenten, para su verificación por parte de la misma Comisión. Este aspecto debe destacarse, ya que las normas no regulan cómo deben conducirse esas observaciones y objeciones.

Por tales motivos, se puede llegar a la conclusión de que hay una profunda afectación a los baluartes del Poder Judicial en Venezuela. Por un lado, a la independencia de su sistema judicial, dado el carácter provisional de los jueces, los cuales pueden ser destituidos sin justificación o procedimiento alguno. De igual manera, y más recientemente, debido a su alineación política al partido de gobierno (Partido Socialista Unido de Venezuela PSUV y al chavismo-madurismo), se ha visto comprometida su imparcialidad, al igual que su independencia, ante las decisiones del poder que debe controlar.

Por lo tanto, en la actualidad se designa a los jueces provisorios sin el previo cumplimiento de los requisitos de ley, cuestión que impide garantizar la imparcialidad que debe existir entre los Poderes Públicos, así como materializar los principios y garantías constitucionales, tales como la tutela judicial efectiva, el debido proceso, la igualdad entre las partes y la seguridad jurídica. De igual manera, paraliza la calificación de los funcionarios para desempeñar tan loable labor. 
En ese orden de ideas, los procesos judiciales y las sentencias con las cuales se pone fin a los mismos, pueden estar (como de hecho lo están en la práctica judicial) marcados por parcialismos políticos o de cualquier otra índole (económicos, sociales, entre otros), especialmente en aquellos casos donde el Estado o los funcionarios del gobierno se hayan visto involucrados ${ }^{69}$.

Esta situación de provisionalidad, que incluso podría definirse como precariedad de los jueces venezolanos, ha sido la regla constante durante los gobiernos de Hugo Chávez (1999-2000, 2001-2006, 2007-2013) y de su sucesor Nicolás Maduro (2013-2019). El Alto Comisionado de las Naciones Unidas para los Derechos Humanos, en su Informe de 2017, indica que la gran mayoría de los jueces venezolanos no son titulares, que pueden ser removidos discrecionalmente por el Ejecutivo y que su nombramiento se produce al margen de lo que establecen las leyes de la República (Oficina del Alto Comisionado de las Naciones Unidas para los Derechos Humanos, 2017).

Solucionar esta situación no solo debe implicar el cumplimiento de la normativa existente en lo relativo al nombramiento de jueces, sino que hace necesaria la reforma del sistema actual, cuyas características, así como las amplias facultades de sus integrantes (particularmente de la Comisión Judicial en el nombramiento de jueces provisorios), están en directa oposición con el texto constitucional y con los principios universalmente reconocidos de la actividad judicial: la autonomía y la independencia.

En relación con ambos principios, la doctrina más destacada sostiene que estos son interdependientes y complementarios. En palabras de Rondón de Sansó (1996),

\footnotetext{
autonomía alude asimismo, a la libertad de actuación del órgano; que se refuerza con la independencia, que es la no sujeción a ningún otro. La autonomía está dada en el texto como sinónimo de libertad del titular del cargo para determinar el contenido de sus actos y el alcance de ellos en cada caso específico, y en obediencia de la ley. Independencia, por parte, tiene el significado de la inexistencia de influencias y controles sobre sus decisiones (p. 111).
}

69 Por ejemplo, el caso contra el diario El Nacional, cuya sentencia fue dictada por la Sala de Casación Civil. Ver: http://www.ntn24.com/america-latina/venezuela/tribunal-ordena-el-nacional-pagar-diosdado-cabello-por-danomoral-90208. 
Es indudable que, en el marco de la actual praxis inconstitucional de nombramiento de jueces, la actividad judicial está siempre sometida al control político y a los intereses de los grupos hegemónicos en el poder. Como señala Germán Silva (2009),

la naturaleza de la estructura organizativa de la administración de justicia es un aspecto macrosocial. Y si conforme a dicha estructura orgánica los jueces carecen de independencia interna o ella se encuentra amenazada, esto repercutirá sobre las prácticas de los operadores judiciales quienes, probablemente, sentirán al momento de tomar sus decisiones las presiones (p. 76).

Entonces, como se puede ver, a pesar de todas las reformas que han tenido lugar, la situación del poder judicial en Venezuela es aún más crítica que en las décadas anteriores. Algunos sectores atribuyen esto a que los mecanismos que han sido adoptados por el Estado se han dirigido a eliminar la independencia del poder judicial y a instaurar un régimen autoritario (Pérez Perdomo, 2004).

Finalmente, surge la cuestión de la legitimidad en la elección de los magistrados del Tribunal Supremo de Justicia, órgano superior del Poder Judicial, que no solo representa la más alta instancia, sino que, en su Sala Constitucional, ejerce las funciones de control e interpretación máxima de los principios supremos de la Carta Magna. Como sostiene Brewer-Carías (2005a),

bajo este ángulo, la cuestión de la legitimidad de la escogencia y designación de los jueces de la Corte Suprema, por tanto, se plantea desde el punto de vista teleológico, con el objeto de analizar los diversos métodos a fin de determinar en qué forma y con qué efectividad, desde su origen, los mismos sirven para garantizar que los jueces, al impartir justicia, sean independientes de los demás poderes del Estado y además, autónomos en el sentido de que decidan con sujeción sólo y estricta a la ley, libres de presiones o intereses políticos (p.1).

La Constitución de la República Bolivariana de Venezuela establece, en sus artículos 262, 263 y 270, los requisitos para la designación y ejercicio de los magistrados. Sobre el caso de los educadores universitarios que opten por dicho cargo, la categoría de profesor titular hace pensar, en principio, que tal término ha de entenderse según lo dicho en la Ley de Universidades, instrumento que instaura las categorías docentes ${ }^{70}$.

70 En el momento de la promulgación de la Constitución de 1999, estaba vigente la Ley de Universidades de 1970, la cual establecía las categorías docentes de: instructores, asistentes, agregados, asociados y titulares. El tiempo 
No obstante, con ocasión de un recurso de nulidad por inconstitucionalidad, el cual intenta la Defensora del Pueblo contra la Ley Especial para la Ratificación o Designación de los Funcionarios o Funcionarias del Poder Ciudadano y Magistrados y Magistradas del Tribunal Supremo de Justicia para el Primer Período Constitucional, la Sala Constitucional del Tribunal, en la Sentencia No. 1562 del 12 de diciembre de 2000, analiza el artículo 263 de la Carta Magna y establece:

La categoría de profesor titular no podría entenderse en el sentido de un grado dentro de la jerarquía de una carrera, ya que la norma para nada se refiere a la carrera universitaria, y a la necesidad de ser profesor a tiempo completo dentro de ella, que es la que permite acceder a los grados superiores; y además, quien ingresa a una universidad como instructor difícilmente puede llegar a la más alta jerarquía en un lapso de quince años. De allí que la categoría de titular tiene que ser entendida como la condición de una persona respecto de las demás (Tribunal Supremo de Justicia, Sala Constitucional, S-1562, 2000).

Esta aclaración cambia el sentido originalmente establecido por el constituyente. Además, es imprecisa, puesto que afirma que se requiere ser profesor universitario a tiempo completo para alcanzar la categoría de titular (exigencia no establecida por la ley) o que difícilmente se puede ascender a la misma en determinado tiempo, cuando la ley sí contempla tal posibilidad.

Por tanto, a la luz de la nueva sentencia, se identifica a un profesor titular con un profesor ordinario, lo que representa una "entronización de la mediocridad y el abandono de la excelencia universitaria” (Brewer-Carías, 2005b, p. 78), al igual que el desconocimiento de la Constitución. Es importante recordar que la exigencia de los más altos estándares de profesionalidad, trayectoria y preparación, debe aplicarse a todos los jueces de la República, para salvaguardar la majestad de la función judicial y para garantizar justicia de calidad a los ciudadanos, en el marco del ordenamiento jurídico democrático que caracteriza a Venezuela desde su Constitución.

En este sentido, Ávila y Ocando (2011), señalan:

La función judicial en un Estado Democrático debe ser la expresión más sublime para alcanzar la libertad y la justicia, por cuanto el poder judicial del Estado es el reflejo del nivel de una sociedad política organizada jurídicamente, que a través de

mínimo que le tomaría a un profesor para alcanzar la categoría de titular sería de quince años. 
sus decisiones tienden a hacer valer la justicia y a proteger al hombre en la plenitud de sus derechos y garantías fundamentales; en ellas la libertad y la igualdad son pilares esenciales en el desarrollo integral de la persona humana... es ahí donde radica la justificación del Poder Judicial en la estructura del Estado y como parte del Poder Público Nacional... la eficacia del orden jurídico depende de la eficiencia y calidad ética o moral de los operadores de justicia encargados de interpretar y aplicar el derecho positivo vigente (p.102).

\section{Análisis de los requerimientos para ser magistrado en Venezuela}

En el sentido de las líneas argumentales discutidas, se analizan los requisitos para ser magistrado en Venezuela, tal y como lo estipula la Constitución en sus artículos 264, 265 y 270.

Respecto a los magistrados del Tribunal Supremo de Justicia se exige, con la finalidad de garantizar la imparcialidad y la independencia en el ejercicio de sus funciones, que desde la fecha de su nombramiento y hasta su egreso de los cargos respectivos, no lleven a cabo, salvo en el ejercicio del voto, activismo político partidista, gremial, sindical o de índole semejante. De igual manera, tampoco pueden realizar actividades privadas lucrativas incompatibles con sus funciones, ni por sí mismos ni por personas interpuestas. Finalmente, no pueden ejercer ninguna otra función pública, a excepción de actividades educativas, e incluso, no pueden asociarse entre sí.

Ahora bien, es relevante mencionar que la designación de magistrados del Tribunal Supremo de Justicia, realizada a finales del 2015, así como las decisiones tomadas por este ente, han sido factor de gran importancia en el devenir de los acontecimientos en el ámbito político en los últimos años. En concreto, a finales del año mencionado, en el lapso correspondiente a la victoria opositora en las parlamentarias y a la entrada en funciones, en enero de 2016, de la nueva Asamblea Nacional, tuvo lugar un retiro anticipado de magistrados designados en el año 2004, generándose el inicio del proceso de sustitución de los mismos por parte de la Asamblea -con mayoría oficialista-, a la que le quedaban muy pocos días de vigencia.

Debido a esto, en su momento, dicho procedimiento contó con un nivel considerable de críticas, que han sido seguidas por menciones desfavorables al funcionamiento del Poder Judicial, en particular en lo que se refiere a la actuación del 
Tribunal Supremo de Justicia. Estas han sido expresadas en informes oficiales por el Secretario General de la Organización de Estados Americanos, Luis Almagro (2017).

Al respecto, cabe destacar que en el mencionado informe se señala que, mediante las sentencias del Tribunal Supremo de Justicia, la actividad legislativa de la Asamblea Nacional ha sido limitada. De hecho, se indica que existe colusión entre el Poder Ejecutivo, el Poder Judicial y el Poder Electoral, de tal forma que se generan cuestionamientos en torno a la aplicación efectiva del principio de separación de poderes.

Dada la importancia de estas actuaciones en el ámbito político, vale preguntarse por el soporte argumental, desde la perspectiva de la Teoría Política, de estas actuaciones del Poder Judicial, siendo pertinente revisar los aportes de autores como Downs y Olson. Por una parte, Downs (1957) caracteriza a los gobernantes como agentes que privilegian fundamentalmente su propio bienestar, lo que implica que su conducta tiene como propósito la captura y la permanencia en el poder. En este caso, la emisión de normas, tanto por el Poder Judicial como por el Poder Electoral, ha facilitado la obtención de dicho objetivo, por parte del actual equipo gobernante en Venezuela.

Por su parte, Olson (2014) plantea que los grupos que tienen acceso a incentivos selectivos, a diferencia de los que no disponen de ellos, actúan con mayor frecuencia de forma colectiva, para obtener bienes comunes. Asimismo, que la probabilidad de actuación de los grupos se incrementa en la medida en que es más reducido su tamaño, ya que esto facilita la negociación entre los actores que los conforman, para actuar de forma coordinada. En este caso, ello se verifica en la medida en que esa actuación ha permitido al actual gobierno en Venezuela permanecer en el poder, teniendo en cuenta que el número de quienes conforman las instancias máximas de decisión (los poderes Ejecutivo, Judicial y Electoral) está en el orden de las centenas de personas.

De igual forma, es menester destacar que esta falta de independencia de los poderes trae consecuencias negativas en el ámbito económico para Venezuela. En concreto, la limitación de las posibilidades de iniciativa legislativa de la Asamblea Nacional genera dificultades para tener acceso a los mercados financieros internacionales. Por otro lado, en el informe de la Secretaría General de la OEA, previamente mencionado, queda plasmado que Venezuela, en el Reporte Mundial de 
Competitividad 2016-2017, publicado por el Foro Económico Mundial, ocupó el último lugar en el indicador de la independencia judicial, en una muestra de ciento treinta y ocho países analizados, lo que produce severos contratiempos para atraer inversiones al país.

En este sentido, cabe destacar que la Conferencia Episcopal Venezolana, en su exhortación pastoral elaborada a principios de 2015, planteó lo siguiente:

Venezuela necesita un nuevo espíritu emprendedor con audacia y creatividad. Es urgente estimular la laboriosidad y la producción dando seguridad jurídica y fomentando empresas eficientes, tanto públicas como privadas. Pero también es necesario observar una conducta ética, recta y honesta (Conferencia Episcopal Venezolana, 2015, p. 2).

Dicho de otro modo, es esencial resaltar que una condición necesaria para la implementación de una propuesta de política económica alternativa, parte de la existencia de independencia judicial. Esto facilita la atracción de inversiones y el inicio de un círculo virtuoso que implica crecientes niveles de producción, recaudación de impuestos y disponibilidad de recursos para atender ámbitos esenciales en la vida de la sociedad, tales como la salud, la educación y la seguridad. Como plantea el artículo 112 de la Constitución (Machado, 2015), es necesario armonizar el ejercicio de la libertad económica con el desarrollo integral del país.

En resumen, es importante señalar que, dado el carácter interdependiente de los derechos humanos (Ávila, Medina \& Urdaneta, 2008), los problemas existentes en Venezuela, en el ámbito judicial, terminan añadiendo dificultades al comportamiento de variables relevantes en lo que concierne a lo económico. Todo eso se termina reflejando en una disminución de la calidad de vida de la sociedad venezolana, lo cual revela la importancia de superar los problemas del sistema judicial, planteados en este trabajo.

\section{Reflexiones finales}

Se ha visto que las cuestiones fundamentales para el desempeño de los Estados Democráticos de Derecho pasan por tener un método de designación de jueces y magistrados cónsonos con las bases de la democracia como sistema político, tal como se señaló en el primer apartado de este documento. Toda democracia que se 
precie de ser un orden de Derecho, ha de estar enlazada con las buenas prácticas políticas, que implican designar un gobierno judicial que esté alejado de presiones y compromisos más allá del principio democrático. El reto que tienen los países inscritos en dicho principio, es el de evitar a toda costa que sus jueces y magistrados ejerzan sus funciones alejados de la autonomía y la independencia, que son los pilares fundamentales de la democracia que rige un Estado de Derecho y de Justicia, como lo proclama la Constitución venezolana en su artículo 2.

Independientemente de cuál sea el modelo de gobierno judicial, lo que se impone como desafío a las democracias es la posibilidad de sortear las influencias del orden político en todo el método de designación de jueces y magistrados. Esto, de la mano de que el propio sistema jurídico legitime la actuación del poder legislativo como garante del cumplimiento de la democracia como valor y de la justicia como su instrumento. No hay democracia sin derecho, como no puede haber derecho sin democracia.

\section{Referencias}

Almagro, L. (2017). Informe de la Secretaría General de la Organización de Estados Americanos -OEA- sobre Venezuela. Recuperado de https://www.oas.org/es/centro_noticias/comunicado_prensa.asp?sCodigo $=\mathrm{C}-056 / 17$

Ávila, F. \& Ocando, H. (2011). El poder judicial venezolano como medio de tutela de los derechos humanos. Revista Opción, 27(66), 98-119.

Ávila, F., Medina, J. \& Urdaneta, A. (2008). Hacia una teoría de los derechos sociales y su justiciabilidad. Revista Cuestiones Políticas, 24(41), 126-146.

Ayala, C. \& Casal, J. (2008). La evolución político-institucional de Venezuela 1975-2005. Revista Estudios Constitucionales, (2), 435-499.

Brewer-Carías, A. (2005a). La cuestión de legitimidad: ¿Cómo escoger los jueces de las cortes supremas? Ponencia presentada en The Future of the European Judicial System. The Constitutional Role of European Courts, 6th International European Constitutional Law Network- Colloquium/International Association of Constitutional Law-Round Table, Berlín, Alemania.

Brewer-Carías, A. (2005b). La progresiva y sistemática demolición de la autonomía e independencia del poder judicial en Venezuela (1999-2004). Texto presentado en Las XXX Jornadas J.M. Domínguez Escovar del Instituto de Investigaciones Jurídicas - Colegio de Abogados del Estado Lara, Barquisimeto, Venezuela.

Capella, J.R. (1997). Fruta prohibida. Una aproximación histórico-teorética al estudio del derecho y del Estado. Madrid: Editorial Trotta. 
Conferencia Episcopal Venezolana. (2015). Exhortación pastoral: renovación ética y espiritual frente a la crisis. Recuperado de https://politikaucab.files.wordpress.com/2015/01/ conferencia-episcopal-venezolana-exhoracic3b2n-pastoral-enero-2015.pdf.

Comisión Interamericana de Derechos Humanos. (2009). Informe Anual de la Comisión Interamericana de Derechos Humanos Capítulo Venezuela. Recuperado de https:// www.cidh.oas.org/annualrep/2009sp/cap.4Venezuela09.sp.htm.

Damiani, L. (2013). Historia del Poder Judicial venezolano: el reto del ingreso a la carrera judicial. Recuperado de http://www.jdj.gob.ve/articulos/Historia\%20del\%20Poder\%20 Judicial\%20venezolano.pdf.

Delgado Ocando, J.M. (1996). Curso de Filosofia del Derecho Actual. Caracas: Vadell Hermanos.

Quiroga dice que nombramiento de jueces en Venezuela busca reducir la mayoría. ( 23 de diciembre de 2015). Diario Las Américas. Recuperado de https://www.diariolasamericas. com/quiroga-dice-que-nombramiento-jueces-venezuela-busca-reducir-la-mayoria-n3530763.

Downs, A. (1957). An Economic Theory of Democracy. New York: Harper \& Brothers Publisher.

Duque Corredor, R. (2005). La manipulación del estado de derecho como instrumento de consolidación de un proyecto político de concentración del poder en Venezuela. Relación presentada en la Mesa Redonda "Lecciones prácticas de la crisis política venezolana”, del Instituto de Investigaciones Jurídicas de la Universidad Autónoma de México, México D.F.

Habermas, J. (1997). El nexo interno entre Estado de Derecho y Democracia. En J.A. Gimbernat (Ed.), La filosofía moral y política de Jürgen Habermas (pp. 23-34). Madrid: Biblioteca Nueva.

Habermas, J. (1998). Facticidad y validez. Sobre el derecho y el Estado democrático de derecho en términos de teoría del discurso. Madrid: Editorial Trotta.

Human Rights Watch (16 de junio de 2014). Manipulando el Estado de Derecho: independencia del Poder Judicial amenazada en Venezuela. [Entrada de blog]. Recuperado de https:/www.hrw.org/es/report/2004/06/16/manipulando-el-estado-de-derecho/ independencia-del-poder-judicial-amenazada-en.

Lawyers Committee for Human Rights. (1996). Halfway to Reform: The World Bank and the Venezuelan Justice System. Recuperado de https://cutt.ly/frLX0bd.

López Guerra, L. (2002). Reflexiones sobre los modelos de gobierno del poder judicial. En J. Vega Gómez \& E. Corzo Sosa (Coord.), Tribunales y justicia constitucional. Memoria del VII Congreso Iberoamericano de Derecho Constitucional (pp. 247-262). México: Universidad Nacional Autónoma de México.

Louza, L. (2005). Relación entre Gobierno Judicial y Administración de Justicia. Reflexiones a la luz del caso "Venezuela". Recuperado de http://www.biblio.dpp.cl/biblio/ DataFiles/14138.pdf. 
Machado, G. (2015). Política económica y marco constitucional en Venezuela: un análisis crítico. Ponencia presentada en el XII Congreso Iberoamericano de Derecho Constitucional de la Universidad Externado, Bogotá, Colombia.

Marín Quijada, E. (1988). Carrera judicial y formación. Papel de trabajo presentado en el Taller sobre programación de capacitación de jueces, ILANUD, San José, Costa Rica.

Melgar, M. (1997). Consejo de la Judicatura Federal. Administración y función jurisdiccional. Revista de Administración Pública, (95), 1.

Observatorio Venezolano de la Justicia (2016). Análisis de las normas de evaluación y concurso para el ingreso y ascenso a la función judicial. Recuperado de https://www.accesoalajusticia.org/consideraciones-sobre-las-normas-de-evaluacion-y-concurso-de-oposicion-para-el-ingreso-y-ascenso-a-la-funcion-judicial/

Oficina del Alto Comisionado de las Naciones Unidas para los Derechos Humanos. (2017). Violaciones y abusos de los derechos humanos en el contexto de las protestas en la República Bolivariana de Venezuela. Recuperado de https://www.ohchr.org/ Documents/Countries/VE/HCReportVenezuela_1April-31July2017_SP.pdf.

Olson, M. (2014). La lógica de la acción colectiva. En A. Battle (Comp.), Diez Textos Clásicos de Ciencia Política (pp. 203-220). España: Editorial Ariel.

Pérez Perdomo, R. (1993). Crisis política y sistema judicial en Venezuela. Revista del Centro de Estudios Constitucionales, 16, 95-112. Recuperado de https://dialnet.unirioja.es/ ejemplar/101888.

Pérez Perdomo, R. (2004). Reforma judicial, estado de derecho y revolución en Venezuela. En L. Pásara (Comp.), En busca de una justicia distinta. Experiencias de reforma en América Latina (pp. 335-374). Lima: Consorcio Justicia Viva.

Pérez Perdomo, R. (2006). Medio siglo de historia judicial en Venezuela (1952-2005). Revista Cuadernos Unimetanos, 11, 3-23. Recuperado de http://www.ulpiano.org.ve/revistas/ bases/artic/texto/RDUNIMET/11/RDUNIMET_2007_11_3-24.pdf.

Quintero, M. (1988). Justicia y Realidad. Universidad Central de Venezuela. Facultad de Ciencias Jurídicas y Políticas. Caracas, Venezuela.

Raynero, L. (Comp.). (2013). Historia de la democracia. Ensayos. Caracas: El Nacional.

Rengel-Romberg, A. (2003). Estudios Jurídicos. Caracas: Academia de las Ciencias.

Rondón de Sansó, H. (1996). Participación de los jueces nacionales en la interpretación prejudicial del ordenamiento jurídico andino. Revista Jurídica Online, (12), 105-127. Recuperado de https://www.revistajuridicaonline.com/wp-content/uploads/1996/09/12_Participacion _de_Jueces_Nacionales_Interp_Prejuicial.pdf.

Roche, C., Richter, J. \& Pérez, N. (2002). Los excluidos de la justicia en Venezuela. Caracas: Ediciones del Tribunal Supremo de Justicia.

Ron, R. \& Lousada, P. (2017). Los Consejos de la Magistratura y otros modelos de gobierno judicial. Anuario da Facultade de Direito da Universidade da Coruña, 21, 300-313. 
Silva García, G. (2009). Teoría Sociológica sobre la Profesión Jurídica y Administración de Justicia. Revista Prolegómenos. Derechos y Valores de la Facultad de Derecho, 12(23), 71-84.

Tribunal Supremo De Justicia, Sala Plena. (28 de septiembre de 2005). Normas de evaluación y concurso de oposición para el ingreso y ascenso a la carrera judicial.

Vilera, M. (2009). El acceso a la función judicial en Venezuela. Revista Venezolana de Economía y Ciencias Sociales, (15), 13-36. Recuperado de http://www.redalyc.org/articulo. oa?id=17721678002>.

Villalobos Antúnez, J.V. (2001). Derecho, racionalidad y el supuesto metodológico de la Modernidad. Utopía y praxis latinoamericana, 6(12), 64-82.

Villalobos Antúnez, J.V. (2016). Justicia y teoría política: una cuestión de pluralismo. Revista Opción, 32(80), 7-10. Recuperado de http://www.redalyc.org/articulo.oa?id=31047691001.

Villalobos Antúnez, J.V \& Bozo, F. (2010). El discurso jurídico y la tesis de indeterminación del derecho de J. Habermas. Frónesis, 17, 379-397. Recuperado de http://www.produccioncientifica.luz.edu.ve/index.php/fronesis/article/view/16499.

Villalobos Antúnez, J. V. \& Ganga, F. (2016). Derechos sociales fundamentales: consideraciones iusfilosóficas de sus dilemas. Aproximación utópica desde la Bioética Global. Utopía y Praxis Latinoamericana, 21(75), 93-111. Recuperado de http://www.redalyc.org/articulo.oa? $\mathrm{id}=27950107010$. 